\title{
KFBD
}

Karadeniz Fen Bilimleri Dergisi

The Black Sea Journal of Sciences

ISSN (Online): 2564-7377

Araștırma Makalesi / Research Article

\section{Au/CuPc/n-Si/In Schottky Diyotunun Üretilmesi ve Akım-Gerilim Karakteristiklerinden Diyot Parametrelerinin Araştırılması}

\author{
Serkan EYMUR ${ }^{1}$, Nihat TUĞLUOĞLU²* \\ ${ }^{1,2}$ Giresun Üniversitesi, Mühendislik Fakültesi, Enerji Sistemleri Mühendisliği Bölümü, Giresun, Türkiye
}

Geliş Tarihi: 31.03 .2020

*Sorumlu Yazar: nihat.tugluoglu@giresun.edu.tr

Kabul Tarihi: 21.04.2020

\section{Öz}

İndiyum (In) omik kontaklı n-Si yarıiletkeni üzerinde döndürme kaplama yöntemi ile bakır ftalosiyanin (CuPc) organik ince film biriktirilmiştir. Doğrultucu kontak oluşturmak için altın $(\mathrm{Au})$ metali isısal buharlaştırma tekniği yardımı ile oluşturulmuştur. Sonuçta $\mathrm{Au} / \mathrm{CuPc} / \mathrm{n}-\mathrm{Si} / \mathrm{In}$ Schottky diyot yapısı üretilmiştir. İdealite faktörü, Schottky engel yüksekliği, doyma akımı, seri direnç ve şönt direnci gibi diyot parametreleri akım-gerilim (I-V) ölçümleri yardımıyla araştırılmış̧ır. $\mathrm{Au}$ ve $\mathrm{n}$-Si arasında biriktirilen $\mathrm{CuPc}$ ince filmi iyi bir doğrultma özelliği göstermiştir. Bu analizde, Schottky engel yüksekliği ve idealite faktörü değerleri oda sıcaklı̆̆ında sırasıyla $0.757 \mathrm{eV}$ ve 2.49 olarak belirlenmiştir. Sonuçlar, üretilen diyodun çeşitli optoelektronik uygulamalarda kullanılabileceğini göstermektedir.

Anahtar Kelimeler: Bakır ftalosiyanin, Schottky engel diyot, akım-gerilim, engel yüksekliği, idealite faktörü.

\section{Fabrication of Au/CuPc/n-Si/In Schottky Diode and Investigation of Diode Parameters from Current-Voltage Characteristics}

\begin{abstract}
Copper phthalocyanine organic thin film was deposited on n-Si semiconductor with indium (In) ohmic contact by the spin coating method. Gold ( $\mathrm{Au}$ ) metal is formed by thermal evaporation technique to form a rectifier contact. As a result, $\mathrm{Au} / \mathrm{CuPc} / \mathrm{n}-\mathrm{Si} / \mathrm{In}$ Schottky diode structure was produced. Diode parameters such as ideality factor, Schottky barrier height, saturation current, series resistance and shunt resistance were investigated by means of current-voltage (I-V) measurements. CuPc thin film deposited between Au and n-Si has shown a good rectifying properties. From this analysis, the values of Schottky barrier height and ideality factor at room temperature have determined as $0.757 \mathrm{eV}$ and 2.49 , respectively. Results show that the fabricated diode can be used in various optoelectronic applications.
\end{abstract}

Keywords: Copper phthalocyanine, Schottky barrier diode, current-voltage, barrier height, ideality factor. 


\section{Giriş}

Organik yarı iletkenler; elektronik(Simonsen ve ark., 2009), optoelektronik (Clark ve Lanzani, 2010) ve fotonik (Capelli ve ark., 2010) cihazlardaki potansiyel uygulamaları nedeniyle artan ilgi görmektedir. Organik yarı iletkenlere dayanan cihaz teknolojisi, inorganik benzerlerine kıyasla nispeten düşük maliyetli ve imal edilmesi kolaydır (Sayyad ve ark., 2010) Yaygın olarak kullanılan ilginç bir yaklaşım, her iki malzeme türünün avantajlarından aynı anda tek bir cihazda yararlanmak için organik-inorganik (OI) heterojeksiyonların üretilmesidir (Güllü ve Türüt, 2008; Aydin ve ark., 2007). Bu tür cihazlarda, organik malzeme, düşük sıcaklık ve yapısal çeşitlilikte güvenilir ince film üretim teknikleri sunarken inorganik malzeme ise bir dizi elektronik, kimyasal ve mekanik özellik ile 1sıl kararlılık sağlar (Akkılıç ve ark., 2010).

MPc (M = iki değerli metaller) formülüne sahip ftalosiyanin (Pc) bileşikleri geleneksel olarak boya ve pigment olarak kullanılmaktadır. MPc, düşük maliyeti ve potansiyel olarak yüksek fotoelektronik özellikleri nedeniyle özel bir ilgi sunmaktadır. Ayrıca, alan etkili transistörler, doğrusal olmayan optikler ve moleküler sensörler için de MPc'nin kullanıldığı çalışmalar mevcuttur (Bao ve ark., 1996). MPc, organik 1şık yayan diyotlar (OLED'ler) (Ishii ve Taga, 2002) ve güneş pilleri (Chen ve ark., 2013) gibi moleküler optoelektronik cihazlar için en umut verici malzemeler olarak tanımlanabilir.

Bakır ftalosiyanin $(\mathrm{CuPc})$, belirgin fotovoltaik etkisi ve foto iletkenlik özellikleri nedeniyle organik güneş pillerinde soğurucu olarak yaygın bir şekilde kullanılmaktadır (Tang, 1986). Temel olarak, CuPc, p tipi bir yarı iletken davranış sergileyen en önemli organik moleküllerden biridir. $\mathrm{CuPc}$, iyi termal, kimyasal kararlılık ve IR bölgesinde uzanan ve kabul edilebilir hareketlilik değerleri ile görünür bölge aralığının ötesinde büyük soğurmanın eşlik ettiği kristal yapısından dolayı aktif bir tabaka olarak kabul edilmiştir (Snow ve Barger, 1989; Forrest, 1997; Prabakaran ve ark., 2008). Bu göze çarpan özellikler CuPc'yi gelecekteki elektronik cihazların geliştirilmesi için potansiyel bir aday haline getirmektedir

$\mathrm{Bu}$ çalışmada, Al/CuPc/n-Si/In Schottky diyot yapısı hem 1sısal buharlaştırma hem de döndürme ile kaplama tekniği kullanılarak hazırlanmıştır. Hazırlanan bu organik/inorganik yarıiletken diyotların elektronik özelliklerini araştırmak amacıyla, karanlık altında akım-gerilim (IV) ölçümleri yapılmıştır. Bu ölçümlerden diyotun ideallik faktörü, engel yüksekliği, doyma akımı, seri direnç ve arayüzey durum yoğunluğu gibi elektronik parametreleri belirlenmiştir. 


\section{Materyal ve Metot}

\subsection{Bakır Ftalosiyanin (CuPc) Organik Yariiletken Özellikleri}

Bakır Ftalosiyanin (CuPc), metal ftalosiyaninlerin bir üyesi olup, molekül formülü $\mathrm{C}_{32} \mathrm{H}_{16} \mathrm{CuN}_{8}$ dir. Şekil 2.1'de CuPc molekülünün yapısal formülü görülmektedir (Schuster ve ark., 2010). CuPc’nin molar kütlesi 576,07 g/mol, erime derecesi $350{ }^{\circ} \mathrm{C}$ ve yoğunluğu $1,59 \mathrm{~g} / \mathrm{cm}^{3}$ dür (URL 1). CuPc’nin boş olan en düsük enerjili moleküler orbitali (LUMO) ve dolu olan en yüksek enerjili moleküler orbitali (HOMO) enerji değerleri sırasıyla 3,5 eV ve 5,2 eV dur (URL 1). CuPc'nin dielektrik sabiti ise 3,52'dir (Singh ve Ravindra, 2010).
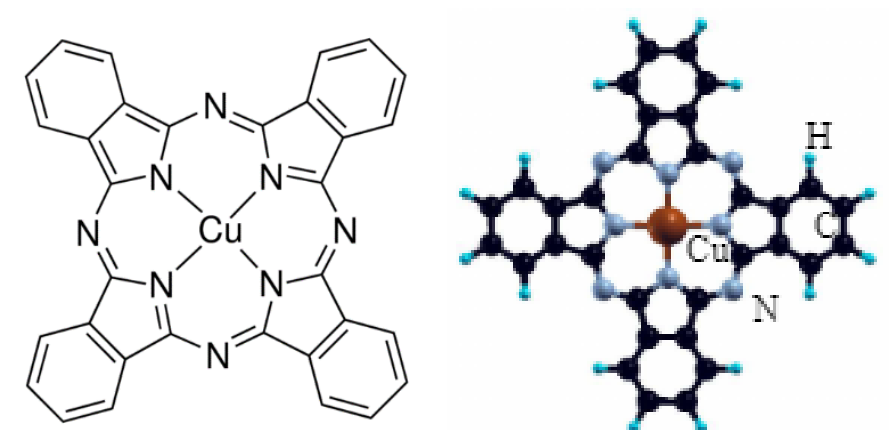

Şekil 1. Bakır Ftalosiyanin (CuPc) molekülünün yapısal formülü $\left(\mathrm{C}_{32} \mathrm{H}_{16} \mathrm{CuN}_{8}\right)$ (Schuster ark., 2010; URL1)

\subsection{Au/CuPc/n-Si/In Schottky Diyotların Üretilmesi}

Bu çalışmada kullanılan Silisyum kristali, fosfor (P) katkılı (yani, n tipi), CZ (Czochralski) tekniği ile büyütülmüş, $20 \Omega$-cm özdirençli, $380 \mu \mathrm{m}$ kalınlığında ve (100) düzleminde $5 \mathrm{~cm}$ çapındadır. İlk olarak, silisyum, yüzeyindeki olası yağları temizlemek için ultrasonic banyoda sırasıyla trikloretilen, aseton ve metanol dolu beherde 10 dakika titreştirilmiş ve her işlemden sonra $18 \mathrm{M} \Omega-\mathrm{cm}$ özdirençli deiyonize su ile ultrasonik banyoda 5 dakika çalkalanmıştır. Silikon yüzeyindeki organik ve inorganik artıkları uzaklaştırımak için, beher içerisine $\mathrm{H}_{2} \mathrm{O}(325 \mathrm{ml})+(27 \%)$ $\mathrm{NH}_{4} \mathrm{OH}(65 \mathrm{ml})$ karışımı konularak ısıtılmıştır (Akgül, 2015). Isıtılan karışıma (30\%) $\mathrm{H}_{2} \mathrm{O}_{2}(65 \mathrm{ml})$ eklenip kabarcıklar oluştuktan sonra silikon kristalleri oluşan yeni karışımın içinde ultrasonik banyoda 15 dakika bekletilmiştir. Daha sonra $18 \mathrm{M} \Omega-\mathrm{cm}$ dirençli deiyonize su ile bolca durulanmıştır. Bu esnada silikon yüzeyinde bir miktar oksit tabakası oluşabileceğinden bu tabakanın etkisini en az düzeye indirebilmek için, teflon beher içerisindeki deiyonize suya (480ml), HF (20ml) 
eklenmiştir. Oluşan karışıma silisyum kristal konularak 2 dakika çalkalanmış, bolca deiyonize su ile durulanmış ve azot $\left(\mathrm{N}_{2}\right)$ gazı ile kurutulmuştur. Daha sonra vakum ortamında isısal buharlaştırma tekniği yardımıyla Omik kontak yapımı için indiyum (In, \% 99.99 saflıkta) metali kullanılmıştır. Omik kontak için $150 \mathrm{~nm}$ indiyum kalınlığına ulaştıktan sonra buharlaştırma işlemi sonlandırılmıştır. Aynı vakum ortamında tungsten levha üzerinde silisyum kristali 1sıtılarak omik kontak oluşturulmuştur. CuPc organik malzemesini çözmek için çözücü olarak amonyak ve etanolden yararlanılmıştır. $10 \mathrm{mg} \mathrm{CuPc}$ 'nin $200 \mathrm{ml}$ amonyak-etanol (1:1) içerisindeki çözeltisi hazırlanmıştır. Si kristalinin parlak yüzeyine Laurell marka döndürme ile kaplama (spin coater) cihazı yardımıyla 50 $\mu 1 \mathrm{CuPc}$ çözeltisi damlatılmıştır. Kaplama cihazı önce 500 devir/dakika’da 30 saniye, daha sonra 1200 devir/dakika'da 60 saniye çalıştırılmıştır. Bu işlem kalın film elde etmek için 5 kez tekrarlanmıştır ve toplamda $250 \mu 1$ çözelti kullanılmıştır. $1 \mathrm{MHz}$ kapasite ölçümlerinden elde edilen CuPc kalınlığı yaklaşık $810 \mathrm{~nm}$ elde edilmiştir. Doğrultucu kontak oluşturmak için yalaşık $2 \mathrm{~mm}$ çaplı deliklere sahip maske seçilmiştir. Vakum odasında basınç 1 x $10^{-5}$ Torr'a ulaşınca doğrultucu kontak için $150 \mathrm{~nm}$ kalınlığında altın (Au, \%99.99 saflıkta) metali biriktirilmiştir.

Sonuç olarak, aynı şartlarda hazırlanmış çok sayıda $\mathrm{Au} / \mathrm{CuPc} / \mathrm{n}-\mathrm{Si} / \mathrm{In}$ Schottky diyot yapısı üretilmiştir. Şekil 2'de silisyum alttabaka üzerinde üretilen Au/CuPc/n-Si/In Schottky diyotların şematik diyagramı görülmektedir. Üretilen Au/CuPc/n-Si/In Schottky diyotların, oda sıcaklığında karanlıkta akım-gerilim (I-V) ölçümleri için Keithley 2400 Source Meter cihazı kullanılmıştır.

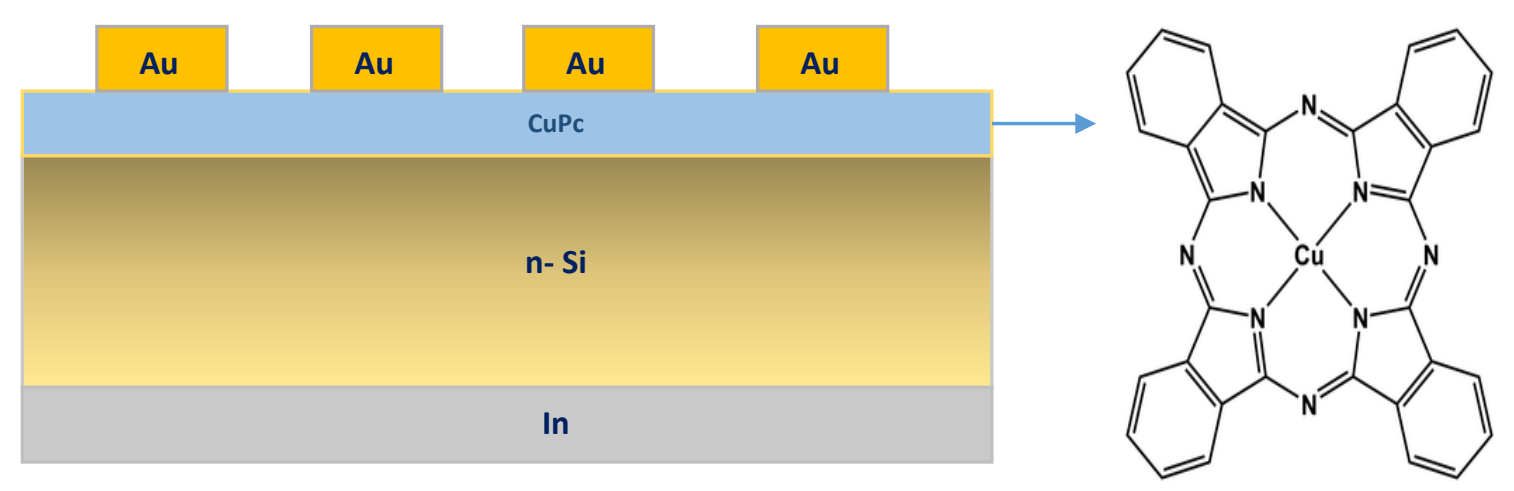

Şekil 2. Au/CuPc/n-Si/In Schottky diyotun şematik yapısı. 


\section{Bulgular ve Tartışma}

\subsection{Akım-Gerilim (I-V) Karakteristiklerinden Diyot Parametre Hesabı}

Şekil 3. de oda sıcaklığında karanlıkta $\mathrm{Au} / \mathrm{CuPc} / \mathrm{n}-\mathrm{Si} / \mathrm{In}$ Schottky diyota ait düz ve ters beslem akım-gerilim (I-V) karakteristiği verilmiştir. Ölçümler -2 V ve $+2 \mathrm{~V}$ arasında alınmıştır. Termiyonik emisyon (TE) teorisine göre, akım ve gerilim arasındaki bağıntı (Sze, 1981; Yüksel ve ark., 2013; Tuğluoğlu ve Karadeniz, 2012),

$I=I_{0}\left[\exp \left(\frac{q V}{k T}\right)\right]$

ile verilir. Burada q elektron yükünü, k Boltzmann sabitini, I akımı, V diyot gerilimini, ve T Kelvin cinsinden sıcaklığı ifade etmektedir. Io çoğunluk taşıyıcıları için ters doyum akımı olup,

$I_{0}=A A^{*} T^{2} \exp \left[\frac{-q \Phi_{B}}{k T}\right]$

ile ifade edilir. Burada $\Phi_{\mathrm{B}}$, A ve A* sırasıyla Schottky engel yüksekliği, diyot alanı ve Richardson sabitidir. İdeal durumdan farklı durumları belirlemek için (1) ifadesine idealite faktörü (n) olarak adlandırılan bir ifade eklenir. Bu durumda (1) denklemi;

$I=I_{0} \exp \left(\frac{q V}{n k T}\right)$

şeklinde ifade edilir. Burada idealite faktörü ara yüzey durumlarına, uygulanan gerilime ve sıcaklığa bağlı olup, değeri 1 'den büyüktür. Elde edilen yapıların ideallik faktörleri yarı logaritmik I-V eğrisinin eğiminden hesaplanmıştır (Denklem 4) (Akgül, 2015; Sze, 1981; Yüksel ve ark., 2013).

$n=\frac{q}{k T} \frac{d V}{d(\ln I)}$

Denklem 2'nin her iki tarafının logaritması alınarak $\Phi_{B}$ ’ye göre çözülürse

$\Phi_{B}=\frac{k T}{q} \ln \left(\frac{A A^{*} T^{2}}{I_{0}}\right)$ 
denklemi elde edilir. (4) ve (5) ifadeleri kullanılarak n ve $\Phi_{\mathrm{B}}$ değerleri belirlenmiştir.

Tablo 1'de karanlıkta ve aydınlık altında Au/CuPc/n-Si/In Schottky diyodu için I-V eğrilerinden elde edilen $n, \Phi_{B}, I_{o}$ ve $N_{s s}$ değerleri verilmiştir. (Khan ve ark., 2011) Au/p-VoPc/n-Si Schottky diyodu hazırlamışlar ve $\mathrm{n}, \Phi_{\mathrm{B}}$ ve $\mathrm{I}_{\mathrm{o}}$ değerlerini sırasıyla 3.42, $0.77 \mathrm{eV}$ ve $60 \mathrm{nA}$ olarak rapor etmişlerdir. (El-Nahass ve ark., 2007) Au/p-NiPc/n-Si Schottky diyodu üretmişler ve n, $\Phi_{B}$ ve $I_{o}$ değerlerini sırasıyla 1.68, $0.55 \mathrm{eV}$ ve $20 \mathrm{nA}$ olarak rapor etmişlerdir. (Baraz ve ark., 2017) Au/biphenyl-CoPc/n-Si diyot hazırlamışlar diyotun n, $\Phi_{B}$ ve $I_{0}$ değerlerini sırasıyla 3.8, 0.84 eV ve 70.5 nA olarak hesaplamışlar ve ayrıca da Au/OHSubs-ZnPc/n-Si diyot üretmişler ve diyotun n, $\Phi_{\mathrm{B}}$ ve $\mathrm{I}_{0}$ değerlerini sırasıyla 4.8, $0.70 \mathrm{eV}$ ve $216 \mathrm{nA}$ olarak rapor etmişlerdir.

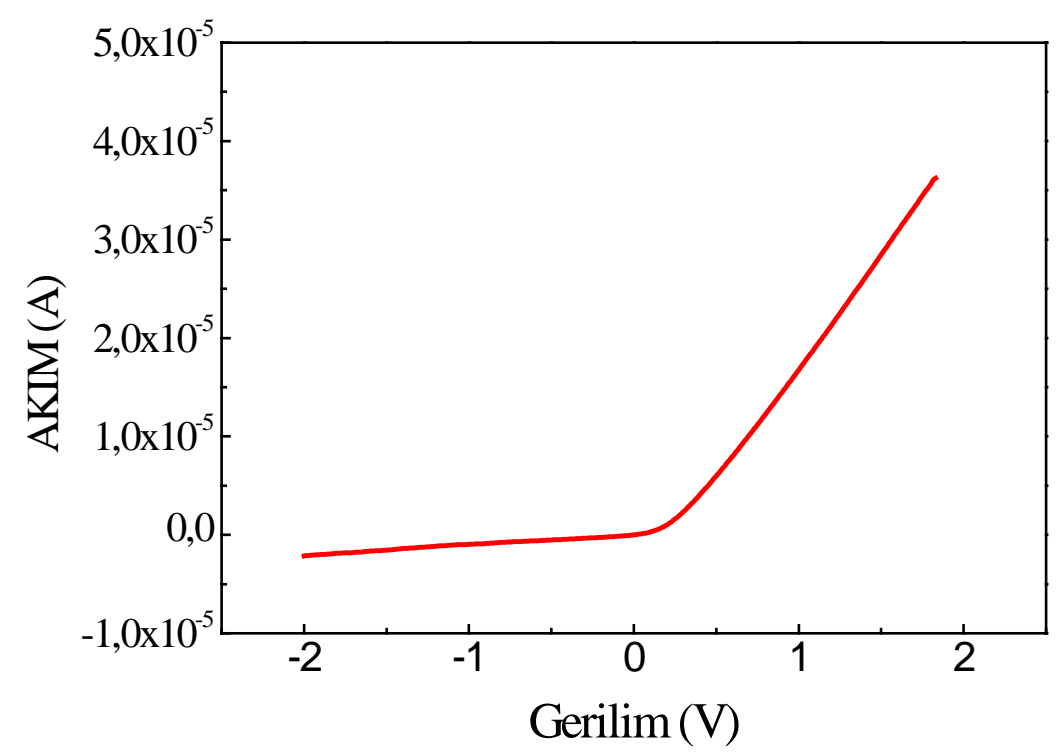

Şekil 3. Au/CuPc/n-Si/In Schottky diyotun karanlık altında düz ve ters beslem I-V karakteristikleri.

Bir Schottky diyot için doğrultma oranları (RR) akım-gerilim grafiğinden denklem (6) kulanılarak elde edilir (Sze, 1981)

$R R=\frac{I_{d}}{I_{t}}$

Denklemde, sabit bir gerilim değerindeki $I_{d}$, düz beslem akımı ve $I_{t}$ ise ters beslem yönündeki akımdır. Au/CuPc/n-Si/In Schottky diyotu için +2 V ve $-2 \mathrm{~V}$ değerleri için karanlıkta doğrultma oranı hesaplanmış ve Tablo 1 de verilmiştir. Tablo 1 incelediğimizde doğrultma oranı karanlıkta 18.34 dir. Elde edilen değerler literatürde rapor edilen Schottky diyotların doğrultma değerleri açısından bakıldığında yeterli olduğu görülmüştür. 
Tablo 1. Au/CuPc/n-Si/In Schottky diyotun karanlıkta altında I-V ölçümlerinden elde edilen diyot parameter değerleri.

\begin{tabular}{|c|c|c|c|c|c|c|c|}
\hline & $n$ & $\begin{array}{c}\Phi_{\mathrm{B}} \\
(\mathrm{eV})\end{array}$ & $\begin{array}{c}\mathrm{I}_{\mathrm{o}} \\
\left(\times 10^{-8} \mathrm{~A}\right)\end{array}$ & $\begin{array}{c}N_{\mathrm{ss}} \\
\left(\times 10^{10} \mathrm{eV}^{-1} \mathrm{~cm}^{-2}\right)\end{array}$ & $\begin{array}{c}\text { RR } \\
( \pm 2 V)\end{array}$ & $\begin{array}{c}\text { Rs } \\
(\mathrm{k} \Omega)\end{array}$ & $\begin{array}{l}\text { Rsh } \\
(\mathbf{k} \Omega)\end{array}$ \\
\hline Karanlık & 2.49 & 0.757 & 6.21 & 3.25 & 18.34 & 36.9 & 368 \\
\hline
\end{tabular}

\subsection{Seri Direnç Hesabı}

Schottky diyotun performansını ve kalitesini anlamak için seri direnç $\left(R_{S}\right)$ ve şönt direnci $\left(R_{S h}\right)$ önemli parametrelerdendir (Sze, 1981). Ohm yasasını $\left(R_{d}=d V_{i} / d I_{i}\right)$ kullanarak düz ve ters beslem I-V karakteristiklerinden yararlanarak uygulanan gerilime bağlı olarak yapının direnci $\left(R_{d}\right)$ hesaplanmış ve Şekil 3.2 de verilmiştir. Düz beslemde $R_{i}$ değerleri minimum değere yaklaşarak seri direnç $\left(R_{S}\right)$ değerini verirken ters beslemde maksimum değere yaklaşarak şönt direnç $\left(R_{s h}\right)$ değeri elde edilmiştir. Karanlıkta ve aydınlıkta elde edilen $R_{S}$ ve $R_{s h}$ değerleri Tablo 3.1'de verilmiştir. $\mathrm{Au} / \mathrm{CuPc} / \mathrm{n}-\mathrm{Si}$ Schottky diyodu için karanlıkta $R_{S}$ ve $R_{s h}$ değerleri sırasıyla $36,9 \mathrm{k} \Omega$ ve $368 \mathrm{k} \Omega$ olarak elde edilmiştir. (Khan ve ark., 2011) Au/p-VoPc/n-Si Schottky diyodu hazırlamışlar ve $R_{S}$ ve $R_{s h}$ değerlerini sırasıyla $1,4 \mathrm{k} \Omega$ ve $0,1 \mathrm{M} \Omega$ olarak rapor etmişlerdir. (El-Nahass ve ark., 2007) Au/p$\mathrm{NiPc} / \mathrm{n}-\mathrm{Si}$ Schottky diyodu üretmişler ve $R_{s}$ ve $R_{s h}$ değerlerini sırasıyla $1,33 \mathrm{k} \Omega$ ve $4,12 \mathrm{M} \Omega$ olarak rapor etmişlerdir. (Baraz ve ark., 2017) Au/biphenyl-CoPc/n-Si ve Au/OHSubs-ZnPc/n-Si diyotları üretmişler ve $R_{S}$ değerleri için sırasıyla $115 \Omega$ ve $62 \Omega$ ve $R_{s h}$ değerlerini de sırasılla $270 \mathrm{k} \Omega$ ve 242 $\mathrm{k} \Omega$ olarak hesaplamışlardır. 


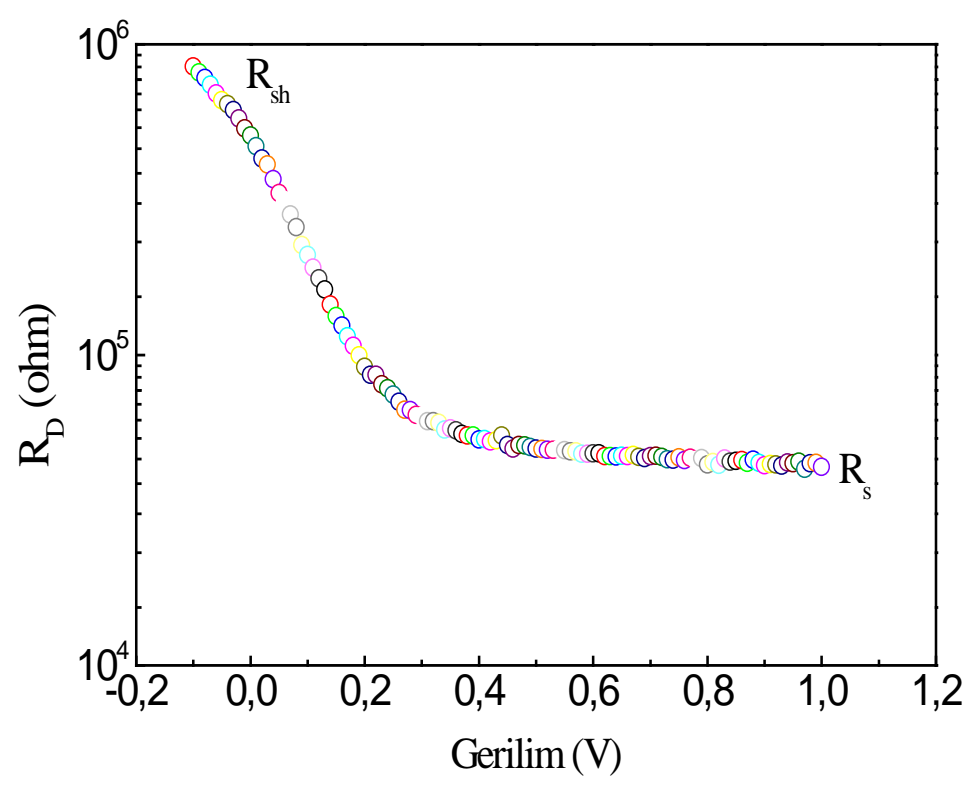

Şekil 4. $\mathrm{Au} / \mathrm{CuPc} / \mathrm{n}-\mathrm{Si}$ Schottky diyot için karanlıkta altında ohm yasasından seri direnç $\left(R_{s}\right)$ ve şönt direnç $\left(R_{\text {sh }}\right)$ değerleri

Seri direnç hesaplama yöntemlerinden bir diğeri de Norde yöntemidir (Norde, 1979). TE Teorisinden bulunan akım yoğunluğu ifadesi diyotun etkin alanıyla çarpıldığında toplam I akımı (qV>>3kT) (Akgül, 2015; Sze, 1981; Yüksel ve ark., 2013);

$I=A A^{*} T^{2} \exp \left(\frac{-q \emptyset_{B}}{k T}\right)\left[\exp \left(\frac{q V}{n k T}\right)-1\right]$

olur. Schottky diyoduna uygulanan $V$ geriliminin bir kısmı da seri direnç üzerine düşeceğinden dolayı (7) ifadesi,

$I=A A^{*} T^{2} \exp \left(\frac{q \emptyset_{B}}{k T}\right)\left[\exp \left(\frac{q(V-I R}{n k T}\right)-1\right]$

şeklini alır. Burada $(V-I R)$ terimi diyot üzerine düşen gerilimdir.

1986'da Bohlin (Bohlin, 1986) ideallik faktörünün 1'den büyük olması durumunda Norde fonksiyonunu yeniden düzenledi. Burada $\gamma$, ideallik faktöründen küçük olmamak üzere $(1<\mathrm{n}<\gamma)$ ilk büyük tam sayıdır. Böylece ideallik faktörü büyük olan diyotlar için $I-V$ ölçümlerinden elde edilen $\mathrm{R}_{\mathrm{s}}, \Phi_{\mathrm{B}}$ ve n'in daha doğru olarak belirlenmesini mümkün kılar. Buna göre modifiye edilmiş yeni Norde fonksiyonu, 
$F(V, \gamma)=F_{R}(V)=\frac{V}{\gamma}-\frac{1}{\beta} \operatorname{Ln}\left(\frac{V}{R A A^{*} T^{2}}\right)$

şeklide ifade edilir. Gerekli düzenlemeler yapıldığında engel yüksekliği ve seri direnç,

$\Phi_{B}=F\left(V_{0}, \gamma\right)-\left(\frac{1}{\gamma}-\frac{1}{n}\right) V_{0}-\frac{(\gamma-\mathrm{n})}{(\beta n)}$

ve

$R_{s}=\left(\frac{\gamma-\mathrm{n}}{\beta I_{0}}\right)$

ifadeleri elde edilir.

Geliştirilmiş Norde (Norde, 1979) metoduna göre Au/CuPc/n-Si Schottky diyot için karanlıkta altında engel yüksekliği ve seri direnç değerleri (9) denklemi yardımıyla çizilen $F(V)-V$ eğrilerinden elde edilmiştir. Şekil 5'de Au/CuPc/n-Si Schottky diyotun karanlıkta altında $F(V)-V$ eğrisi görülmektedir. Şekil 5 incelendiğinde karanlıkta ve aydınlık altında diyota ait $F(V)$ fonksiyonu bir minimumdan geçmektedir. (10) ve (11) denklemlerinden $\Phi_{B}$ ve $R_{S}$ değerleri belirlenmiştir ve Tablo 2 de verilmiştir. (Oruç ve Altındal, 2018) Au/FePc/p-Si Schottky diyotu hazırlamışlar ve Norde metoduna göre $\Phi_{\mathrm{B}}$ ve $R_{S}$ değerlerini sırasıyla $0.84 \mathrm{eV}$ ve $165.6 \mathrm{k} \Omega$ hesaplamışlardır.

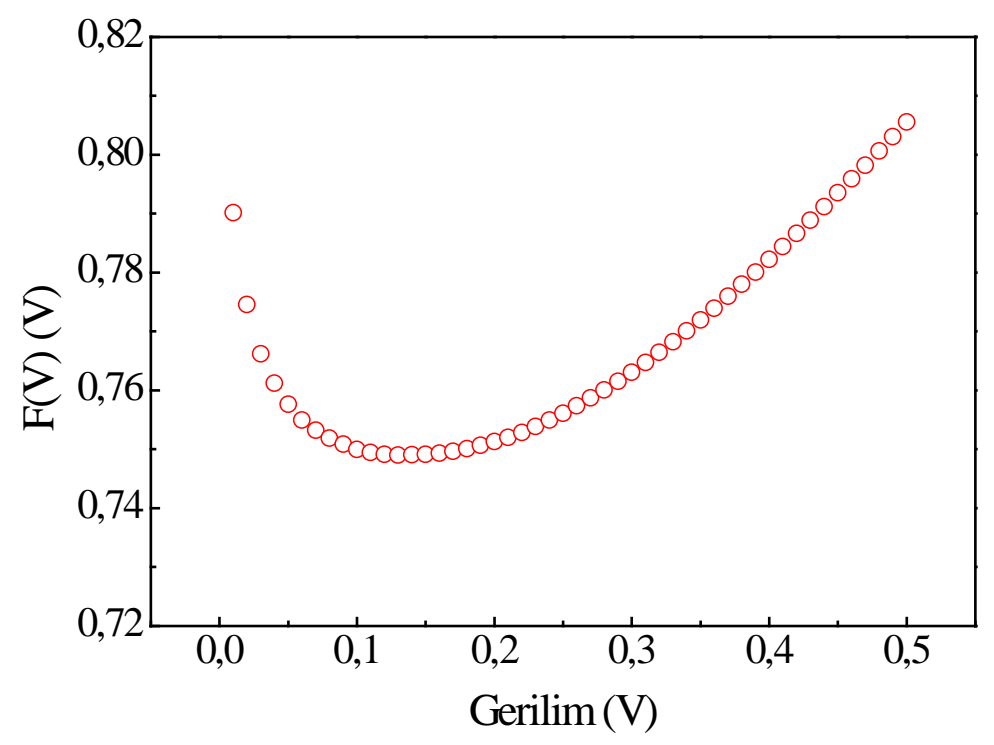

Şekil 5. Au/CuPc/n-Si Schottky diyodun karanlık altında $F(V)-V$ karakteristikleri. 
Tablo 2. Au/CuPc/n-Si Schottky diyodun karanlıkta altında Norde metodu F(V) fonksiyonu yardımıyla elde edilmiş $\Phi_{\mathrm{B}}$ ve $\mathrm{R}_{\mathrm{S}}$ değerleri.

\begin{tabular}{|c|c|c|c|c|c|}
\hline & $\begin{array}{c}\mathbf{R s} \\
(\mathbf{k} \Omega)\end{array}$ & $\begin{array}{c}\Phi_{\mathrm{B}} \\
(\mathrm{eV})\end{array}$ & $\begin{array}{c}\mathrm{F}\left(\mathrm{V}_{\mathbf{0}}\right) \\
(\mathrm{V})\end{array}$ & $\begin{array}{c}\mathbf{V}_{\mathbf{0}} \\
(\mathrm{V})\end{array}$ & $\begin{array}{c}\mathbf{I}_{\mathbf{0}} \\
\left(\times 10^{-7} \mathrm{~A}\right)\end{array}$ \\
\hline Karanlık & 44.5 & 0.751 & 0.750 & 0.10 & 2.96 \\
\hline
\end{tabular}

\subsection{Arayüzey Durum Yoğuluğu Hesabı}

Arayüzey durumları, yariiletken yasak enerji bant aralığında olup belirli bir yoğunluğa sahiptir. $I-V$ karakteristikleri yardımıyla Schottky diyotların arayüzey tuzak yoğunlukları $\left(\mathrm{N}_{\mathrm{ss}}\right)$ değeri (Akgül, 2015; Sze, 1981)

$N_{S S}=\frac{1}{q}\left(\frac{\varepsilon_{i}}{\delta}(n(V)-1)-\frac{\varepsilon_{S}}{W_{D}}\right)$

ifadesinden elde edilmiştir. n-tipi bir yarıiletken için iletim bandının alt seviyesine göre arayüzey durumlarının enerjileri $\left(E_{s s}\right)$ (Akgül, 2015; Sze, 1981);

$E_{c}-E_{S S}=q\left(\Phi_{e}-V\right)$

ile verilir. Denklem 12 ve 13'de verilen ifadelerde, q elektron yükü, $\delta$ arayüzey tabakası kalınlığg, $W_{D}$ tükenim tabakası genişliği, $\varepsilon_{i}$ arayüzey katmanı geçirgenliği $(\mathrm{CuPc}=3.5 \mathrm{~F} / \mathrm{cm}), \varepsilon_{s}$ yarıiletken geçirgenliği $(11,8 \mathrm{~F} / \mathrm{cm})$ olarak ifade edilir.

$\mathrm{Au} / \mathrm{CuPc} / \mathrm{n}-\mathrm{Si}$ Schottky diyodun karanlık altında arayüzey durum yoğunluğunun enerjiye bağlı dağılımı Şekil 6' da verilmiştir. Yasak enerji bant aralığının ortasından başlayarak bir minumumdan geçen arayüzey durumları, iletim bandının alt seviyesine doğru artış göstermektedir. Tablo 1'de $\mathrm{Au} / \mathrm{CuPc} / \mathrm{n}-\mathrm{Si}$ Schottky diyodun karanlık altında hesaplanan ortalama arayüzey durumlarının değerleri verilmiştir. Arayüzey durumların değerleri karanlıkta $0.591 \mathrm{eV}$ ta $2.33 \times 10^{11} \mathrm{eV}^{-1} \mathrm{~cm}^{-2}$ ve $0.716 \mathrm{eV}$ 'ta $3.24 \times 10^{10} \mathrm{eV}^{-1} \mathrm{~cm}^{-2}$ olarak elde edilmiştir. Elde edilen değerleri baktığımızda karanlıkta arayüzey durumların yoğunluğu iletim bandına doğru azalmakta valans bandına doğru ise artmaktadır. 


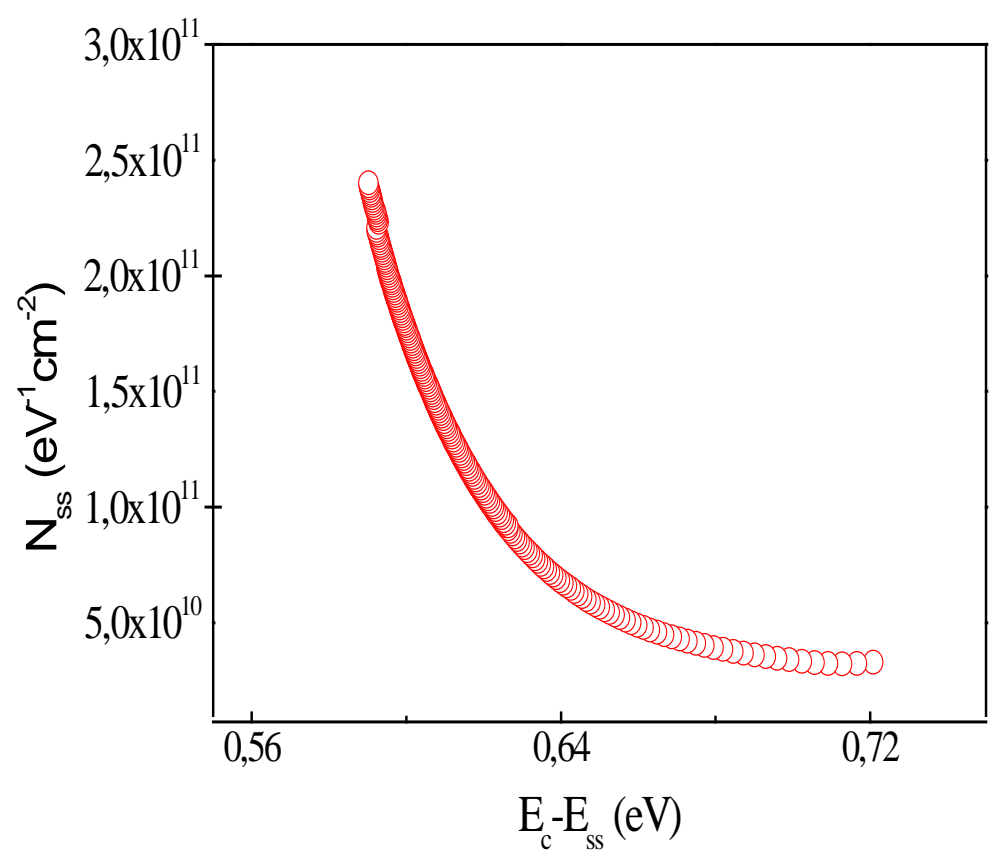

Şekil 6. Au/CuPc/n-Si Schottky diyodun karanlık altında arayüzey durum yoğunluklarının enerjiye bağlı dağılımları.

\section{Sonuçlar ve Öneriler}

Au/bakır ftalosiyanin (CuPc)/n-Si/In Schottky diyot yapısı üretildi. Tipik Schottky diyot yapısı gözlendi. Bu gözlemden yararlanarak, karanlıkta akım-gerilim (I-V) ölçümlerinden idelite faktörü, engel yüksekliği, doyma akımı, seri direnç, şönt direnci ve arayüzey durum yoğunluğu gibi diyot karakteristik parametreleri elde edildi. CuPc organik filmin, diyotun elektriksel parametreleri üzerine etkisi incelenmiştir. I-V karakteristiklerden, karanlıkta altında Au/CuPc/n-Si/In Schottky diyot idealite faktörü, engel yüksekliği, ara yüzey durum yoğunluğu değerleri sırasılla $2.49,0.757 \mathrm{eV}$ ve $3.25 \times 10^{10} \mathrm{eV}^{-1} \mathrm{~cm}^{-2}$ olarak belirlenmiştir. Üretilen diyot, organik/inorganik heteroeklemlerin elektronik uygulamalarında kullanılma potansiyeline sahiptir.

\section{Teşekkür}

Bu çalışma, FEN-BAP-C-09112017-163 proje numarası ile Giresun Üniversitesi Bilimsel Araştırma Projeleri Ofisi tarafından desteklenmiştir. 


\section{Kaynaklar}

Akgül, K.B. (2015). Aynı şartlar altında üretilen özdeş Au/n-Si (100) Schottky diyotlarda karakteristik parametrelerin belirlenmesi. Yüksek Lisans Tezi, Gazi Üniversitesi, Fen Bilimleri Enstitüsü, Ankara.

Akkılıç, K., Ocak, Y., Kılıçoğlu, T., Ilhan, S. And Temel, H. (2010). Calculation of current-voltage characteristics of a Cu (II) complex/n-Si/AuSb Schottky diode. Current Applied Physics, 10, 337-341.

Aydin, M.E., Yakuphanoglu, F., Eom, J.-H. and Hwang, D.-H. (2007). Electrical characterization of Al/MEHPPV/p-Si Schottky diode by current-voltage and capacitance-voltage methods. Physica B, 387, 239.

Baraz, N., Yücedağ, İ., Demir, A., Ersöz, G., Altındal, Ş. and Kandaz, M. (2017). Controlling the electrical characteristics of $\mathrm{Au} / \mathrm{n}-\mathrm{Si}$ structure with and without (biphenyl-CoPc) and (OHSubs-ZnPc) interfacial layers at room temperature. Polymers Advanced Technologies, 28, 952-957.

Bao, Z., Lovinger, A.J. and Dodabalapur, A. (1996). "Organic field-effect transistors with high mobility based on copper phthalocyanine. Applied Physics Letters, 69, 3066.

Bohlin, K.H. (1986). Genaralized Norde plot including determination of the ideality factor. Journal of Applied Physics, 60, 1223-1224.

Capelli, R., Toffanin, S., Generali, G., Usta, H., Facchetti, A. and Muccini, M. (2010). Organic light-emitting transistors with an efficiency that outperforms the equivalent light-emitting diodes. Nature Materials, 9, 496.

Chen, X., Taguchi, D., Manaka, T. and Iwamoto, M. (2013). Study of blocking effect of Cu-phthalocyanine layer in zinc oxide/pentacene/CuPc/ $\mathrm{C}_{60} / \mathrm{Al}$ organic solar cells by electric field-induced optical second harmonic generation measurement. Organic Electronics, 14, 320-325.

Clark, J. and Lanzani, G. (2010). Organic photonics for communications. Nature Photonics, 4, 438.

El-Nahass, M.M., Abd-ül-Rahman, K.F. and Darwish A.A.A. (2007). Fabrication and electrical characterization of p-NiPc/n-Si heterojunction. Microelectronics Journal, 38, 91-95.

Forrest, S.R. (1997). Ultrathin Organic Films Grown by Organic Molecular Beam Deposition and Related Technique. Chemical Review, 97, 1793-1896.

Güllü, Ö. and Türüt A. (2008). Photovoltaic and electronic properties of quercetin/p-InP solar cells. Solar Energy Materials Solar Cells, 92, 1205-1210.

Ishii, M. and Taga, Y. (2002). Influence of temperature and drive current on degradation mechanisms in organic light-emitting diodes. Applied Physics Letters, 80, 3430.

Khan, S.M., Sayyed, H.H. and Karimov, K.S. (2011). Investigation of temperature-dependent electrical properties of p-VOPc/n-Si heterojunction under dark conditions.

Ionics, 17, 307-313.

Norde, H.A. (1979). Modified forward I-V plot for schottky diodes with high series resistance. Journal of Applied Physics, 50, 5052-5054.

Oruç., Ç and Altındal, A. (2018). Comparative study of I-V methods to extract Au/FePc/p-Si Schottky barrier diode parameters. Applied Physics A, 124, 81-88.

Prabakaran, R., Fortunato, E., Martins, R. And Ferreira, I. (2008). Fabrication and characterization of hybrid solar cells based on copper phthalocyanine/porous silicon. Journal of Non Crystalline Solids 354, 2892 2896.

Sayyad, M.H., Saleem, M., Karimov, K.S., Yaseen, M., Ali, M., Cheong, K.Y. and Noor, A.F.M. (2010). Synthesis of Zn(II) 5,10,15,20-tetrakis(4'-isopropylphenyl)porphyrin and its use as a thin film sensor. Applied Physics A, 98, 103.

Schuster, C., Kraus, M., Opitz, A., Brütting, W. and Eckern, U. (2010). Transport properties of copper phthalocyanine based organic electronics devices. The European Physical Jornal Special Topics, 80, 117-134.

Singh, P. and Ravindra, N.M. (2010). Optical properties of metal phthalocyanines. Journal of Materials Sience, 45, 4013-4020.

Simonsen, J., Handke, B., Li, Z. and Møller, P. (2009). A study of the interaction between perylene and the $\mathrm{TiO}_{2}(110)-(1 \mathrm{x} 1)$ surface-based on XPS, UPS and NEXAFS measurements. Surface Science, 603, 1270.

Snow, A.W., Barger, W.R. (1989). in Phthalocyanines: Properties and Applications, (VCH Publishers, New York) (Chapter 5).

Sze, S. M. (1981). Physics of Semiconductor Devices (Second edition). New York:John Wiley \& Sons, 362390.

Tang C.W. (1986). Two-layer organic photovoltaic cell. Applied Physics Letters, 48,183. 
Tuğluoğlu, N. and Karadeniz, S. (2012). Analysis of current-voltage and capacitance-voltage characteristics of perylene-monoimide/n-Si Schottky contacts. Current Applied Physics, 12, 1529-1535.

URL 1: https://www.ossila.com/product/cupc

Yüksel, Ö. F., Tuğluoğlu, N., Gülveren, B., Şafak, H. and Kuş, M. (2013). Electrical Properties of Au/perylene-monoimide/p-Si Schottky Diode. Journal of Alloys and Compounds, 577, 30-36. 